\title{
High-temperature Corrosion of Water-wall in Supercritical Boiler
}

\author{
Ling Pan ${ }^{\mathrm{a}}$, Guangyuan $\mathrm{Ma}^{\mathrm{b}}$ and Shunan $\mathrm{Cao}^{\mathrm{c}}$ \\ School of Power and Mechanical Engineering, Wuhan University, Wuhan, Hubei, China \\ alingp2009@126.com, bwhumgy@126.com, shunancao@163.com
}

\begin{abstract}
Keywords: Power Plant; Water-wall; High-temperature Sulfur Corrosion; Corrosion Mechanism; Prevention Method

Abstract. With the development of large capacity and high parameters of power plant boiler, water wall high temperature sulfur corrosion of coal-feed boiler is becoming more and more frequent. Some of these corrosion even have affected the boiler operation safety. In this review, the domestic research in high temperature sulfur corrosion was summarized, combining with the foreign corresponding research, discussed the types of corrosion and the formation mechanism, and factors which affecting the corrosion, and the prevention methods.
\end{abstract}

\section{Introduction}

With the development of China's national economy, the government makes huge efforts to control environmental pollution. Building supercritical boiler which energy consumption and pollutant emissions are relatively low becomes the trend of the construction of power plants [1,2]. With the application of large-capacity and high-parameter boiler, high-temperature corrosion occurred more frequently, and has seriously affected the safe operation of power plant [3]. In terms of high-temperature of water-wall of power plant boiler, researchers conducted a lot of research work and considered that the sulfur in coal is the main reason [4]. Currently, coal types and sulfur content are usually inconsistent with design values [5]. Inferior coal could easily cause the corrosion of water-wall, and may even lead to water-wall burst [6]. According to the survey, China power plants water-wall leakage and burst accidents caused by corrosion and erosion have accounted for about $80 \%$ of total accidents of boiler [7]. Therefore deep research of water-wall sulfur corrosion is significant. This review will summarize in four aspects from characteristics of corrosion, corrosion mechanism, influence factors, and prevention measures.

\section{Corrosion Characteristics}

High-temperature corrosion area of tangential firing boiler usually occurs consistently with slag deposition area at burner and partial upper zone [8]. High-temperature corrosion area of opposed firing boiler are usually found on both sides that are not installed burner [9]. The color of corrosion products are usually brown or tan, and has irregular cracks in the outer surface of water-wall. Corrosion products have obvious stratification with water-wall outside surface. Visible surface of the water-wall tube after scraping corrosion products is density but has irregular dent and pitting [10]. Corrosion products are divided into light areas and dark areas. Dark areas are loose and have plenty of pores. Light areas are dense. According to the scanning electron microscope (SEM) observation, corrosion products are generally single loose layer structure. There are lots of cracks in the corrosion layer and substrate interface, and corrosion products are easy to fall off [11]. Using detecting methods such as energy spectrum analysis and X-ray diffraction detects the corrosion product. Iron, sulfur, oxygen elements are mainly distributed in corrosion layer. Corrosion products are mainly iron sulfide and iron oxides [10].

\section{Corrosion Mechanism [12]}

High-temperature corrosion of water-wall includes sulfide type corrosion caused by Sulphur and $\mathrm{H}_{2} \mathrm{~S}$, and sulfate type corrosion. 
Sulfide Type Corrosion. The main reason of sulfide type corrosion is boiler sidewall area under reducing atmosphere. Pulverized coals combusting under anoxic conditions produce $\mathrm{H}_{2} \mathrm{~S}$ and Sulphur. $\mathrm{H}_{2} \mathrm{~S}$ and Sulphur react with iron and iron oxide to produce iron sulfide and iron oxide.

Sulphur Caused Corrosion. Elemental sulfur in pulverized coal will produce a certain amount of Sulphur during combustion process. Sulphur can easily react with carbon steel to produce FeS in $350 \sim 400^{\circ} \mathrm{C}$ which can cause sulfur corrosion. At the beginning of $450^{\circ} \mathrm{C}$, its damage effects to the water-wall are quite serious. Reactions are shown as Table 1.

Table 1 Sulphur produced reactions

\begin{tabular}{|c|c|}
\hline $\mathrm{FeS}_{2} \rightarrow \mathrm{FeS}+[\mathrm{S}]$ & $(1)$ \\
\hline $2 \mathrm{H}_{2} \mathrm{~S}+\mathrm{SO}_{2} \rightarrow 2 \mathrm{H}_{2} \mathrm{O}+3[\mathrm{~S}]$ & $(2)$ \\
\hline $2 \mathrm{H}_{2} \mathrm{~S}+\mathrm{O}_{2} \rightarrow 2 \mathrm{H}_{2} \mathrm{O}+2[\mathrm{~S}]$ & $(3)$ \\
\hline $3 \mathrm{FeS}_{2}+12 \mathrm{C}+8 \mathrm{O}_{2} \rightarrow \mathrm{Fe}_{3} \mathrm{O}_{4}+12 \mathrm{CO}+6[\mathrm{~S}]$ & $(4)$ \\
\hline $\mathrm{H}_{2} \mathrm{~S} \rightarrow \mathrm{H}_{2}+[\mathrm{S}]$ & $(5)$ \\
\hline $\mathrm{Fe}+[\mathrm{S}] \rightarrow \mathrm{FeS}$ & $(6)$ \\
\hline
\end{tabular}

Sulphur can penetrate the protective film on the water-wall, and infiltrate along the grain boundaries of metal, promoting inside vulcanize. At the same time, the oxide film is loose, cracked and even easy to peel off.

$\mathrm{H}_{2} \mathrm{~S}$ Caused Corrosion. When water-wall surface under reducing atmosphere, $\mathrm{H}_{2} \mathrm{~S}$ is released from coal, causing water-wall seriously corroded. If the wall temperature is within the range of $300 \sim 500^{\circ} \mathrm{C}$, the corrosion rate and the wall temperature increase exponentially. The corrosion rate doubles when temperature increased by $50^{\circ} \mathrm{C} . \mathrm{H}_{2} \mathrm{~S}$ has strong penetration effect, thus it would pass through the layer of loose $\mathrm{Fe}_{2} \mathrm{O}_{3}$ and dense $\left(\mathrm{Fe}_{2} \mathrm{O}_{3} \cdot \mathrm{FeO}\right)$, and reacted with $\mathrm{FeO}$ and $\mathrm{Fe}$ of water-wall. Reactions are shown as Table 2.

Table $2 \mathrm{H}_{2} \mathrm{~S}$ caused corrosion reactions

\begin{tabular}{|c|c|}
\hline $\mathrm{Fe}+\mathrm{H}_{2} \mathrm{~S} \rightarrow \mathrm{FeS}+\mathrm{H}_{2}$ & (7) \\
\hline $\mathrm{FeO}+\mathrm{H}_{2} \mathrm{~S} \rightarrow \mathrm{FeS}+\mathrm{H}_{2} \mathrm{O}$ & $(8)$ \\
\hline
\end{tabular}

FeS can be further oxidized to form iron oxide. The mixture of iron oxide and sulfide is porous and cannot afford protective effect, which can lead to continuing corrosion.

Sulfate Type Corrosion [13]. Coal, power plants typically used, contains alkali metal element, which produce their oxide after combustion. Water-wall corrosion products often contain large amounts of sulfur and alkali metal, typically in the form of sulfate, pyrosulfate and three sodium ferric sulfate. Alkali metal and sulfur gradually increase from surface to inside. According to the reacting phases, sulfate type corrosion is mainly divided into two kinds: (1) Molten sulfate corrosion reacted with $\mathrm{SO}_{3}$; (2) Molten alkali pyrosulfate corrosion.

Molten Sulfate Corrosion Reacting with $\mathrm{SO}_{3}$. This type of sulfate corrosion refers to a process which the molten sulfate absorbed $\mathrm{SO}_{3}$, under the catalysis of $\mathrm{Fe}_{2} \mathrm{O}_{3}$ and $\mathrm{Al}_{2} \mathrm{O}_{3}$, and produces compound sulfate $(\mathrm{Na}, \mathrm{K})(\mathrm{Fe}, \mathrm{Al})\left(\mathrm{SO}_{4}\right)_{3}$. Reactions are shown as Table 3.

Table 3 Molten sulfate corrosion reactions

\begin{tabular}{|c|r|}
\hline $3 \mathrm{Na}_{2} \mathrm{SO}_{4}+\mathrm{Fe}_{2} \mathrm{O}_{3}+3 \mathrm{SO}_{3} \rightarrow 2 \mathrm{Na}_{3} \mathrm{Fe}\left(\mathrm{SO}_{4}\right)_{3}$ & $(9)$ \\
\hline $3 \mathrm{~K}_{2} \mathrm{SO}_{4}+\mathrm{Fe}_{2} \mathrm{O}_{3}+3 \mathrm{SO}_{3} \rightarrow 2 \mathrm{~K}_{3} \mathrm{Fe}\left(\mathrm{SO}_{4}\right)_{3}$ & $(10)$ \\
\hline $3 \mathrm{~K}_{2} \mathrm{SO}_{4}+\mathrm{Al}_{2} \mathrm{O}_{3}+3 \mathrm{SO}_{3} \rightarrow 2 \mathrm{Na}_{3} \mathrm{Al}\left(\mathrm{SO}_{4}\right)_{3}$ & $(11)$ \\
\hline
\end{tabular}

Molten Alkali Pyrosulfate Corrosion. Pyrosulfate existence temperature is in a range of $400 \sim 590^{\circ} \mathrm{C}$, affected by the atmosphere of $\mathrm{SO}_{3}$ content. When $\mathrm{SO}_{3}$ content is lower than the required content, pyrosulfate cannot exist. At the temperature range of $400 \sim 480^{\circ} \mathrm{C}$, fireside corrosion is mainly caused by pyrosulfate. Reactions are shown as Table 4.

Table 4 Molten alkali pyrosulfate corrosion reactions

\begin{tabular}{|c|c|}
\hline $3 \mathrm{Na}_{2} \mathrm{~S}_{2} \mathrm{O}_{7}+\mathrm{Fe}_{2} \mathrm{O}_{3} \rightarrow 2 \mathrm{Na}_{3} \mathrm{Fe}\left(\mathrm{SO}_{4}\right)_{3}$ & $(12)$ \\
\hline $3 \mathrm{~K}_{2} \mathrm{~S}_{2} \mathrm{O}_{7}+\mathrm{Fe}_{2} \mathrm{O}_{3} \rightarrow 2 \mathrm{~K}_{3} \mathrm{Fe}\left(\mathrm{SO}_{4}\right)_{3}$ & $(13)$ \\
\hline
\end{tabular}

Due to the low melting point, pyrosulfate could easily become molten phases in the adhesive layer, which leads to higher reaction speed of corrosion. 


\section{Influence Factors}

Influence of Coal Characteristic. The sulfur content in coal is the internal conditions of high-temperature sulfur corrosion. Higher the content of sulfur and alkali metal and its oxides is, higher the corrosive substance content is higher, thus caused the greater likelihood of high-temperature corrosion [14]. Large particle coal is not flammable, and easy to form a reducing atmosphere. Meanwhile the coal powder would also impact water-wall, damaging the oxide protection film [15]. The ignition temperature of uninflammable coal is relatively high. With ignition delayed, long flame and incomplete combustion, it can easily produce reducing atmosphere on water-wall, which cause high-temperature corrosion [15].

Influence of Oxidizing Atmosphere. Reducing atmosphere is due to the hypoxia combustion of coal. In order to reach environmental requirements, and limiting $\mathrm{NO}_{\mathrm{x}}$ emission, currently most supercritical boilers use low oxygen combustion [16]. Insufficient amount of air exacerbate hypoxia would sequentially produce corrosive gas such as $\mathrm{H}_{2} \mathrm{~S}$ and reducing gas such as $\mathrm{CO}, \mathrm{H}_{2}$, caused the reducing atmosphere [17]. Under the reducing atmosphere, higher CO content means higher possibility of corrosion. On the one hand, it can penetrate in the water-wall oxide film and cause corrosion. On the other hand, it can promote the production of corrosive gas. Besides, under reducing atmosphere ash melting point is $150 \sim 300^{\circ} \mathrm{C}$ which is lower than that under oxidizing atmosphere, causing ash deposited faster, and leading to more serious damage of corrosion [14].

Influence of Water-wall Temperature. The supercritical boiler water-wall minimum temperature is generally above $400^{\circ} \mathrm{C}$. High-temperature corrosion rate and water-wall temperature have an exponential relationship. If the water-wall temperature is within range of $400 \sim 500^{\circ} \mathrm{C}$, corrosion rate doubles when water-wall temperature increased $50^{\circ} \mathrm{C}$ [18]. At the same time, during boiler operation, the steam side of water-wall will form a certain amount of scale, increasing the water-wall temperature, and accelerating corrosion rate [19]. Besides, when combustion system layout is inappropriate or when wind divided unreasonable in operation process, water-wall temperature rises and accelerates corrosion rate [20]. After the AGC being put into operation, frequent changes of load can easily cause water-wall temperature fluctuating dramatically, sometimes even over temperature and putting threat to water-wall safe operation [21].

\section{Prevention Measures}

Control Operation Condition. Controlling fuel quality to insure the sulfur content in coal is less than $0.8 \%$. Blending the high sulfur content coal with other coal while burning is an effective way to reduce the sulfur content [22]. Controlling the size of coal powder $\mathrm{R}_{90}$ at about $10 \%$, can prevent powder impacting water-wall. Establish a perfect inspection system [23]. On the one hand, install flue gas composition monitoring system. On the other hand, use boiler maintenance time to inspect the water-wall [24].

Weaken Reducing Atmosphere. Reducing atmosphere near the water-wall is an important factor of high-temperature corrosion. Weakening reducing atmosphere can provide well effect of corrosion control [20].

Change Combustion Condition. Some methods used to change combustion condition show above such as: Adjusting aerodynamic field; according to fuel characteristic and combustion equipment characteristics determining reasonable excess air coefficient and appropriate amount of oxygen in different load, adjusting the air volume matching [24]. However, low $\mathrm{NO}_{\mathrm{x}}$ emissions are conflict with weakening reducing atmosphere, which needs to increase capacity of denitrification equipment to relieve pressure of $\mathrm{NO}_{\mathrm{x}}$ emission control [5]. But some papers suggest that changing combustion condition cannot effectively weaken reducing atmosphere [25].

Use Sidewall Air-blowing Technology. Sidewall air-blowing technology is a kind of boiler reforming technologies which installs air outlet at the high-temperature area to weaken reducing atmosphere. It can divide into two kinds: closing-to-wall type and jet type [26]. Closing-to-wall air outlet is generally installed on the water-wall fin at corrosion area. Air through outlet into boiler will 
form a layer of air protective film on water-wall. It changes the reducing atmosphere around water-wall. $\mathrm{H}_{2} \mathrm{~S}$ content will decrease $80 \%$ in the atmosphere [9]. Jet type air outlet install on the upper corrosion area of water-wall. Strong rigid jet cause turbulence of high temperature upper flue gas, prompting reducing ingredient oxidation, making fuel gas around water-wall neutral or oxidizing [27]. Sidewall air-blowing technology has now achieved a remarkable success on high-temperature corrosion prevention of the supercritical boiler [25]. However, using this technology is relatively complicated. Applied sidewall air-blowing technology needs to reform boiler, and adjust the volume and angle of outlet air [27]. Meanwhile because of the increasing of the air volume in boiler, $\mathrm{NO}_{\mathrm{x}}$ emission is increased [25].

Improve Corrosion Resistance of Water-wall Tube. To improve corrosion resistance of water-wall tube, it can replace water-wall tube in the corrosion area into corrosion resistance pipe, such as Multi-principal elements alloy, installing refractory belt in the serious damage zone, or use thermal spray technology or electric arc spray technology to spray alloy on water-wall tube, such as $\mathrm{Ni}-\mathrm{Cr}$, $\mathrm{Ni}-\mathrm{Cr}-\mathrm{Al}, \mathrm{Fe}-\mathrm{Cr}-\mathrm{Al}$. This methods can prevent the occurrence of high-temperature corrosion, and prolong service time $[28,29,30]$.

\section{Conclusions}

Internal cause of water-wall high-temperature sulfur corrosion is the high sulfur content in coal. External cause is high temperature and reducing atmosphere of water-wall surface. In view of protection method research of high-temperature corrosion are mainly from two aspects: weakening reducing atmosphere and improving corrosion resistance of water-wall tubes. Sidewall air-blowing technology and electric arc spraying technology have achieved good application performance, but these methods have disadvantages of high cost and are difficult to construct to a certain extent. Currently, the study of high-temperature corrosion mainly focuses on engineering practice, so it is lack of corrosion kinetics research. At present, the application of protection methods and detection of corrosion extent mostly rely on experience. It also cause that we can only rely on increasing frequency of pipe-cut-inspection to prevent water-wall burst. Aiming at this problem, researchers should focus more on corrosion kinetics studies in the future to improve prediction accuracy of corrosion situation. In order to prevent the occurrence of high-temperature sulfur corrosion and attenuate the damage of corrosion.

\section{References}

[1] Jun Jin. Coupling of High-Temperature Corrosion and Erosion Wear Studies under Wall Tangentially Fired, Harbin Institute of Technology, 2014. (In Chinese)

[2] Qiang huang, Journal of Changsha University of Science and Technology (Natural Science), 2013(04):93-97. (In Chinese)

[3] Quan Gao, Study on the Mechanism of Slagging and High Temperature Corrosion of Coal-Combustion Boiler, Huazhong University of Science and Technology, 2007. (In Chinese)

[4] Effect of Char and Sulfur Rich Deposits on Waterwall Corrosion, EPRI, Palo Alto, CA: 2002. 1007097.

[5] Haiyuan Sun, Huadian Technology, 2015(07):29-31. (In Chinese)

[6] Yonggang Zhou, Pei Li, Xiang Ao, Journal of Zhejiang University (Engineering Science), 2015(09):1768-1775. (In Chinese)

[7] Anna Li, Study on Fireside Corrosion of Ultra-Supercritical (USC) Steel, Dalian University of Technology, 2013. (In Chinese)

[8] Zhongyi Deng, Yongsheng Yu, Hong Xie, Electric Power, 2015(01):47-51. (In Chinese) 
[9] Tao Xu, Min Li, Chunxi Li Thermal Power Generation, 2015(08):104-108. (In Chinese)

[10] Yongbing He, Weijun Wang, Changming Li, Electric Power Construction, 2010(10):61-66. (In Chinese)

[11] Superheater Corrosion in Ultra-Supercritical Power Plants: Long-Term Field Exposure at TVA's Gallatin Station, EPRI, Palo Alto, CA,: 1999. TR-111239.

[12] Kefa Cen, Jianren Fan, Boiler and hear exchanger deposit, scorification, wear and corrosion prevention theory and calculated methods, Science Press, Beijing, 1994. (In Chinese)

[13] Superheater Corrosion: Field Test Results, EPRI, Palo Alto, CA,: 1993. TR-103438.

[14] Yujie Liu, On a Typical Power Plant Boiler Failure and Protection, Beijing University of Chemical Technology, 2014. (In Chinese)

[15] Guangjun Wu, Boiler Water-wall High-Temperature Corrosion Thermal Analysis Kinetics Research Imitated in Lab, Zhejiang University, 2005. (In Chinese)

[16] Dinghui Wang, Study on Combustion Characteristics and Lower-NOx Technology for Pulverized Coal Boiler, North China Electric Power University, 2014. (In Chinese)

[17] Waterwall Wastage Mechanisms in Coal-Fired Boilers: The Effect of Coal Chemistry onWaterwall Wastage, EPRI, Palo Alto, CA: 2001. 1004021.

[18] Dingnan Cheng, Zhixiang Zhang, Bao Bian, Journal of China Society of Power Engineering, 2012(11):891-897. (In Chinese)

[19] Kelu Chen, Hongjian Rao, Huadian Technology, 2012(05):8-9. (In Chinese)

[20] Gong Qian, Chang Che, Linfeng Qian, China Special Equipment Safety, 2015(S1):59-64. (In Chinese)

[21] Jiawei Zhang, Zhonghua Zhang, Zhenjie Zhang, Northeast Electric Power Technology, 2013(10):24-30. (In Chinese)

[22] Xin Shi, Friend of Science Amateurs, 2013(11):60-61. (In Chinese)

[23] Hongguo Liu, Hui Cai, Liying Tang, Corrosion and Protection, 2009(08):577-578. (In Chinese)

[24] Yingchi Zhou, Thermal Power Generation, 2013(07):138-141. (In Chinese)

[25] Minsheng Chen, Xiaochun Liao, Jie Lou, Power System Engineering, 2013(05):33-34. (In Chinese)

[26] Qingfeng Jiao, Bin Yao, Gang Cheng, Hunan Electric Power, 2004,24(2):5-8. (In Chinese)

[27] Huabo $\mathrm{Xu}$, High Temperature Corrosion Protection of Boiler Water-wall and Reduce NOx Emission with Sidewall Air-blowing Technology, Tsinghua University, 2004. (In Chinese)

[28] Ping Li, Shengjiao Pang, Tingju Li, Rare Metal Materials and Engineering, 2015(08):1919-1923. (In Chinese)

[29] Laima Luo, Microstructure, properties and mechanism of high velocity arc-sprayed $\mathrm{FeMnCrAl} /$ carbide coatings, Zhejiang University, 2010. (In Chinese)

[30] Ping Huo, Jianping Wang, Jia Li, Boiler Technology, 2009(03):58-61. (In Chinese) 